\title{
Logic management of leadership strategy from the perspective of value innovation
}

\author{
Fei Wang ${ }^{1}$ \\ ${ }^{1}$ Xinhua College, Sun Yat-sen University Guangzhou, China
}

\begin{abstract}
The reason why many enterprises can not achieve high growth is that their leadership and management strategic logic is still limited by the traditional management logic based on competition. However, in order to obtain sustained high growth, we must take customer value as the guidance and carry out value innovation, so as to make enterprises form lasting competitive advantages that are hard to imitate.
\end{abstract}

\section{INTRODUCTION}

Innovation is the most critical and difficult strategic choice faced by the top leaders of enterprises, and it has a very high risk of failure. Through the comparative study of some high growth companies and their competitors, it is found that the main difference lies in the differences in the strategic methods of leadership management. The difference in this method does not lie in the fact that leaders and managers prefer to choose some kind of analysis tool or planning model, but lies in the differences in the basic and internal premise assumptions of the company managers for the strategy. Enterprises with weak competitiveness adopt the traditional strategic logic method: their strategic management thinking is dominated by this idea - to maintain a leading position in the competition. In contrast, high growth companies are not interested in catching up or beating their rivals. On the contrary, they use the management strategy logic of value innovation to make competitors irrelevant.

\section{EASE OF USE}

\subsection{An overview of Value Innovation Logic}

In essence, value innovation is to constantly provide new products or service values that meet the needs and preferences of customers. From the perspective of value innovation, the ultimate goal of leadership strategy is to obtain competitive advantage by providing customer value. Only when enterprises provide customers with more valuable products and services to meet the changing needs and preferences, can enterprises obtain competitive advantages. Under the circumstances of increasingly fierce market competition and changing customer demand, some enterprises have realized the rapid growth of profits and profits, while some enterprises have gradually declined or even went bankrupt. The reason for this phenomenon is not that the analytical tools or formation modes of enterprise strategy formulation are better than those of competitors, but that the leaders and managers have different basic and internal perspectives on strategy, that is, the logical differences of leadership strategy.

As the core content of enterprise management strategy orientation, customer value innovation is to provide customers with more valuable products and services, which requires enterprises to change the traditional competitive strategy logic and transfer the leading logic of leadership strategy to customer value innovation.

Senior leaders influence the strategic orientation of value innovation, and strategic leadership can have an important impact on the overall organization. Bennis (1985) believes that leadership is" one of the most easily perceived and most difficult phenomena in the world". As for the definition of leadership, there are different definitions from different angles or sides. Comprehensive analysis, leadership can be expressed as: leadership is an action process that guides and influences individuals or organizations to achieve certain goals under certain conditions. Among them, the person who implements the guidance and influence is called the leader, and the person who receives the guidance and influence is called the leader. Certain conditions refer to the environmental factors. The essence of leadership is an interactive process between people.

\subsection{Value Innovation Logic vs. traditional strategic logic}

The logic of value innovation and traditional strategic logic are different in four aspects of strategy. These differences determine what kind of problems leaders will ask, find and seek opportunities, and how to understand risks.

- In the traditional strategic logic, there is a concept of strategic group, which refers to a group of enterprises in the industry that adopt the same or similar strategy on 
the same strategic elements. Which strategic group an enterprise is in determines the essential characteristics of competitive strategy. Under the guidance of this strategic logic, many companies think that the conditions of their industry are established, and formulate corresponding strategies.

Value innovation enterprises are not. No matter how other enterprises operate, he jumps out of the strategic group and applies the strategy completely different from that of other enterprises in the group, instead of fighting with its competitors for impossible big cake in the established strategic framework. Value innovation enterprises seek to make a great leap in creativity and value, and break through the fixed pattern of industry thinking.

- In the traditional strategic logic, through the analysis of internal environment, an enterprise can decide what it can do, that is, the behavior supported by its unique resources, capabilities and core competitiveness. Value innovator leaders will not pay too much attention to their existing core competitiveness, but regard themselves as new entrants with nothing. They will throw away the existing competitive advantages which can not further bring customer value. In fact, these so-called core competitiveness may become the sunk cost of enterprises. They should start from the beginning and start from the customer's point of view, rather than from the perspective of customers If you think about what you do, you won't be blinded by your existing resources and abilities.

Value innovators will not be biased or constrained by their own state in a certain period of time. As a result, value innovators are not only more likely to see where customer value exists and how it is changing, but also more likely to act accordingly.

- The traditional strategic logic contains a very important content is the analysis of competitors. Enterprises often spend a lot of energy to understand the analysis of competitors, and then establish the expected response files for each competitor to help enterprises achieve success in the industry. The strategic thinking of many organizations is determined by competitors. They compare their strengths and weaknesses with their rivals and focus on building strengths. They are in a very passive state in the market, which will only bind their own hands and feet, unable to play their own ability.

Because value innovators don't focus on competition, they can distinguish the factors that generate superior value from all competitors in the industry. They don't do the same thing just because competitors use their resources to provide certain products and services. Companies that follow the logic of value innovation liberate resources to explore and provide a new source of value. Ironically, although value innovators are not committed to creating competitive advantage in the first place, they tend to win the biggest competitive advantage and make the competitors unimportant.

- There are two ways to provide value for most products / services, one is to provide acceptable benefits at low cost, or to provide highly differentiated products / services at an acceptable price. In short, customers should either compromise on products / services or pay higher prices for personalized products / services. The value innovation makes customers satisfied with the products / services and prices that they value most, which undoubtedly greatly improves the value of customers.

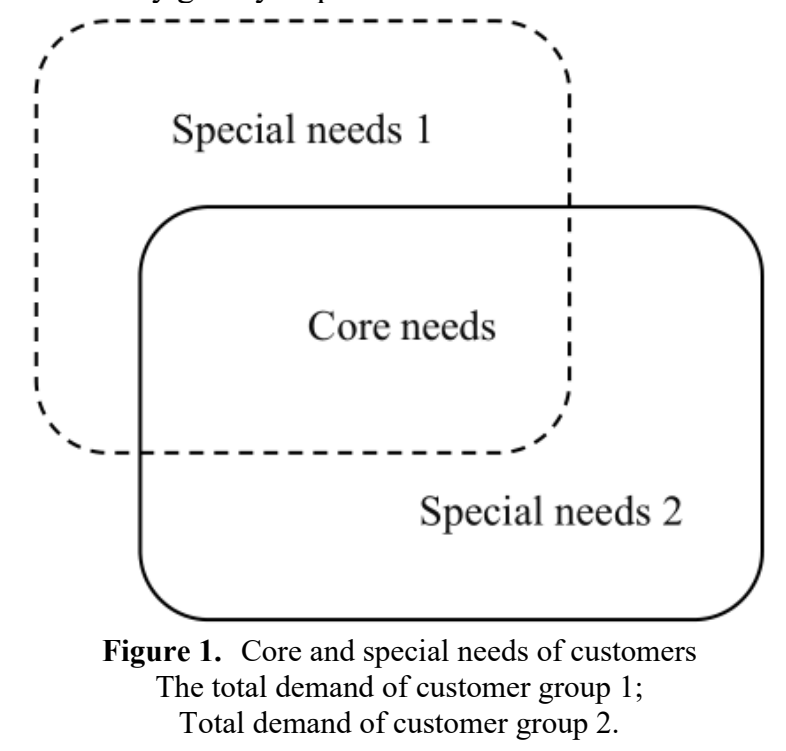

In the traditional strategic logic, many companies seek growth by retaining and expanding their customer base. This usually leads to a more fragmented market and more customized products / services to meet specific needs. In fact, such special needs are not the core needs of customers. Perhaps providing these special needs will make customers feel different, but it can not be at the cost of making significant compromises on their core needs. Many enterprises differentiate for the sake of difference, which only provides some dispensable features, but ignores the factors most valued by customers. Value innovation follows a completely different logic. Value innovators do not pay attention to the differences between customers, but seek strong common ground from some characteristics valued by customers, that is, the core needs of customers, and seek development on this basis. In fact, although the special needs of customers in different market segments are different, the core needs of most customers are based on which to seek development. In fact, although the special needs of customers in different market segments are different, the core needs of most customers are basically the same. (as shown in Figure 1), and only after these core requirements have been met will customers evaluate the special needs provided by the enterprise. Value innovators believe that if the value they provide increases significantly, most people will put the difference aside. Such companies aim at the heart of the market, even if it means losing some of their customers. In essence, the differentiation of traditional strategic logic does not create more customer value for customers. Many enterprises blindly differentiate, resulting in increased costs and prices, but not satisfied with customers, but reduced customer value.

From the above analysis, we can see that the logic of value innovation has the advantages of both low-cost strategy and differentiation strategy under the traditional marketing strategy, that is to provide customers with 
products and services even better than those provided by differentiation strategy through very low cost.

\section{Factor Selection Matrix of Products / SERVICES}

How should business leaders choose product / service factors to innovate? Here is a factor selection matrix to help business leaders make decisions.

According to the different emphases of value innovation and traditional strategic logic on core customer value and competition, this paper gives a matrix, through which the fundamental differences between the two can be explained more clearly. See Figure1.

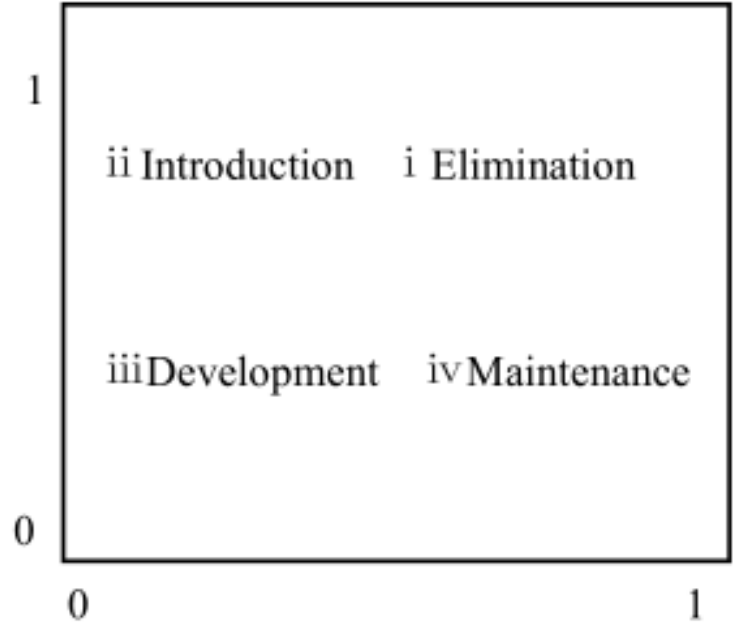

Figure 2. Product / service factor selection matrix

- Each factor of product / service is scored from two aspects of the degree of competition and the core customer value. The value is $0-1$, and then the center of the circle is its coordinate, and the cost invested by the enterprise in this factor is drawn as an area.

- Among them, the industry, that is, a certain established traditional strategic logic, determines the degree of competition of each factor, while the customer preference determines the core customer value. Therefore, the core customer value of each factor under different strategies is the same, but the degree of competition is different.

- The factors in the first quadrant are the factors to continue to develop. Because the factors in this quadrant are highly competitive, which indicates that they are the factors existing in the industry, and because these factors can bring value to customers, they should continue to develop;

- The factors in the second quadrant are the factors never mentioned in the industry that the enterprise will create. The low degree of competition of these factors shows that the industry has basically ignored them, but these factors can bring high value to customers, which is the traditional strategic logic that makes customers make a major compromise. Even like other enterprises in the industry, value innovators do not have the resources and capabilities in this field, and they need to increase investment. However, because these factors are exactly the factors to create lasting advantages, they can make enterprises stand out;

- The factors in the third quadrant bring lower value and lower competition, which are the factors that traditional strategic logic thinks can not bring special needs to customers, but they are the most basic needs of customers. Therefore, they should be retained and appropriately higher than the industry standards, but there is no need to invest too much cost;

- The factors in the fourth quadrant are the factors that should be eliminated by value innovation enterprises. Because the value brought by these factors is very low, only the traditional strategic logic wishful thinking is the special needs of customers, so the fierce competition factors. In fact, the input of these factors only increases the cost and does not bring value to customers, but greatly reduces customer value. Therefore, value innovation enterprises abandon these factors.

- Obviously, according to the above analysis, in order to realize value innovation, enterprise leaders should strive to increase investment in the factors in the second quadrant and reduce the costs of the factors in the fourth quadrant.

- In fact, the factor in the second quadrant is that the traditional strategic logic forces customers to make major compromises. The factors in this quadrant are the factors that can make enterprises break through the industry boundaries and bring value innovation.

- Using this matrix, the paper makes a comparative analysis of two traditional strategies in the industry: differentiation strategy and low-cost strategy. Here, because there are two kinds of traditional strategies in the industry -- differentiation strategy and low-cost strategy, and these two strategies have different emphases on the factors in different strategic choices of leaders. Compared with low-cost strategy, value innovation strategy leads to high investment in the most important factors in the market, improves customer satisfaction, and abandons some high costs But there is no value factor, so the total value has not been greatly improved, only higher than the value of low-cost strategy.

Through the matrix, we can see the differences between the value innovation strategy and the traditional differentiation strategy and low-cost strategy, and we can see that the traditional strategic logic makes customers make a major compromise on the price or product quality at least on one hand, while the value innovation strategy effectively combines the advantages of the two traditional strategic logics that seem incompatible Customer value can be reflected in the strategic decision of value innovation.

\section{SUMMARY}

To sum up, if enterprise leaders want to achieve high growth in today's competitive economic era, they should change their strategic logic. Instead of being competitive oriented and allowing competitors to decide what decisions they should make, they should focus on their customers and let them determine their strategic direction. This seems to ignore the competition, but in fact, it just 
obtains the persistent competitive advantage that the traditional strategic logic has been pursuing.

Define abbreviations and acronyms the first time they are used in the text, even after they have been defined in the abstract. Abbreviations such as IEEE, SI, MKS, CGS, $\mathrm{sc}$, dc, and rms do not have to be defined. Do not use abbreviations in the title or heads unless they are unavoidable.

\section{ACKNOWLEDGEMENT}

1) The reform of international trade practice curriculum under the new format of higher education teaching reform project No. F2018J051 in Guangdong Province is based on the perspective of "cross-borer e-commerce entrepreneurship".

2) This research was supported by the public management project of Guangdong Province in 2016

3) Guangdong provincial department of education 2017 youth innovative talents program (Humanities and social science) No. 2017WQNCX158

\section{REFERENCES}

1. Wu Xuanhong, Chen Sa; customer development strategy based on customer value analysis $[\mathrm{J}]$; Journal of Chongqing University (NATURAL SCIENCE EDITION); issue 07, 2005

2. Performance impact of middle managers' adaptive strategy implementation: The role of social capital[J] . Michael Ahearne,Son K. Lam,Florian Kraus. Strat. Mgmt. J. . 2014 (1)

3. Environmental context, managerial cognition, and strategic action: an integrated view $[\mathrm{J}]$.
SuchetaNadkarni,Pamela S.Barr. Strat. Mgmt. J. . 2008 (13)

4. Review of the research on the role of middle managers $[\mathrm{J}]$. Xie Hefeng, he qiaohui. Management engineer. $2015(05)$

5. Song Luping; on the relationship between value evaluation and value management $[\mathrm{J}]$; management informatization in China; issue 14, 2011

6. Zhou Yongming; enterprise process management based on value management thought; Guangxi University; 2006

7. Discourse and Audience: Organizational Change as Multi-Story Process[J] . DavidBuchanan, PatrickDawson. Journal of Management Studies . 2007 (5)

8. Executive support, organizational identity and strategic implementation of middle managers -- with implementation commitment as the intermediary [J]. Hua Bin, Chen Chuanming. Business Economics and management. 2014 (10)

9. An empirical study on the impact of middle-level managers' multi role behavior on enterprise performance [J]. Fan Yun, Ji Xiaopeng, Zou Yi. Journal of management engineering. 2012 (02)

10. Research on strategic training needs analysis of middle managers based on line of sight theory [D]. Song Wenhui. Nanjing University of Aeronautics and Astronautics, 2013

11. Research on the formation of organizational strategy from the perspective of middle managers [D]. Jia Zhengxin. Nanjing University, 2013 